\title{
Prevalence and clinical features associated with bipolar disorder polypharmacy: a systematic review
}

\author{
This article was published in the following Dove Press journal: \\ Neuropsychiatric Disease and Treatment \\ 31 March 2016 \\ Number of times this article has been viewed
}

\section{Michele Fornaro' \\ Domenico De Berardis ${ }^{2}$ \\ Ann Sarah Koshy ${ }^{3}$ \\ Giampaolo Perna ${ }^{4}$ \\ Alessandro Valchera ${ }^{5}$ \\ Davy Vancampfort ${ }^{6}$ \\ Brendon Stubbs 7,8}

'New York Psychiatric Institute, Columbia University, New York, NY, USA; ${ }^{2}$ National Health Service, Department of Mental Health, Psychiatric Service of Diagnosis and Treatment, Hospital "G. Mazzini”, Teramo, Italy; ${ }^{3} \mathrm{St}$. John's National Academy of Health Sciences, Bangalore, India; ${ }^{4}$ Department of Clinical Neurosciences, Hermanas Hospitalarias - Villa San Benedetto Menni Hospital, FoRiPsi, ${ }^{5}$ Hermanas Hospitalarias, FoRiPsi Villa S.

Giuseppe Hospital, Ascoli Piceno, Italy; ${ }^{6}$ Department of Rehabilitation Sciences, KU Leuven, Leuven, Belgium; 'Physiotherapy Department, South London and Maudsley NHS Foundation Trust, ${ }^{8} \mathrm{Health}$ Service and Population Research Department, Institute of Psychiatry, King's College London, London, UK

Correspondence: Michele Fornaro New York State Psychiatric Institute, Columbia University, 105I Riverside Drive, Unit 42, Room 2729, New York, NY 10032, USA

Tel + I 6467745000

Email dott.fornaro@gmail.com
Background: Uncertainty exists regarding the prevalence and clinical features associated with the practice of polypharmacy in bipolar disorder (BD), warranting a systematic review on the matter.

Methods: Three authors independently searched major electronic databases from inception till September 2015. Articles were included that reported either qualitative or quantitative data about the prevalence and clinical features associated with polypharmacy in adult cases of BD.

Results: The operative definitions of polypharmacy adopted across varying studies varied, with concomitant use of two or more psychotropic medications or use of four or more psychotropic medications at once being the most common and the most reliable, respectively. Regardless of type or current mood episode polarity of BD, prevalence rates up to $85 \%$ and $36 \%$ were found using the most permissive (two or more medications at once) and the most conservative (four or more) operative definitions for polypharmacy, respectively. Point prevalence prescription rates of one or more antidepressant or antipsychotic as part of a polypharmacy regimen occurred in up to $45 \%$ or $80 \%$ of the cases, respectively, according to the most permissive definition of polypharmacy. In contrast, lithium prescription rates ranged from $13 \%$ to $33 \%$ in $\mathrm{BD}$ patients receiving polypharmacy according to conservative and permissive definitions, possibly suggesting a reduced need for augmentation of combination strategies for those cases of BD with a favorable lifetime lithium response and/or long-lasting treatment as well as less likelihood of lithium response over the time most severe cases possibly exposed to a more complex polypharmacy overall.

Limitations: "Apples and oranges" bias; publication bias for most recently introduced compounds.

Conclusion: Polypharmacy is common among people with BD across varying type and mood episode phases of illness. Special population, including BD patients at high risk of familial load for suicidal behavior, solicit further research as well as the plausible "protective" role of lithium toward polypharmacy in BD. The PROSPERO registration number is CRD42014015084.

Keywords: bipolar disorder, polypharmacy, prevalence, systematic review

\section{Introduction}

Bipolar patients include an eclectic mix of ages and diagnostic categories across varying states of health, often receiving complex and long-lasting pharmacological interventions. In a community study, up to $9 \%$ of psychiatric patients received polypharmacy. ${ }^{1}$ These rates increase to $13 \%$ in general population and an alluring $90 \%$ in general psychiatric settings. ${ }^{2}$ Polypharmacy point prevalence rates up to $40 \%$ (according to the definition of three or more medications at once) or 18\% (in case of four or more concomitant medications) have been reported for bipolar disorder (BD) cases suffering from long-lasting and/or treatment-resistant depression and receiving antidepressant drugs. ${ }^{3}$ Furthermore, most of the available information about psychiatric 
medications comes from drug development programs that lead to registration and marketing. These programs almost invariably study the new drug in isolation vs either placebo or a comparator agent. ${ }^{4}$ Experience with any new psychiatric medication in combination with another intervention is therefore virtually limited to a few short-term drug-drug interaction studies that are usually conducted in carefully screened young healthy volunteers. ${ }^{5}$ Nevertheless, the practice of polypharmacy in BD represents the rule rather than the exception in the clinical setting, regardless of the current polarity of mood episode..$^{3,6-8}$ A number of reasons endorse the clinical practice of polypharmacy, with failure to achieve remission being the most common one. ${ }^{9}$ This reflects the findings from the most comprehensive "real-world" pharmacological trial on BD patients to date, the Systematic Treatment Enhancement Program for Bipolar Disorder (STEP-BD), ${ }^{10}$ in which up to $42 \%$ of the symptomatic patients included at baseline did not achieve recovery within 2 years of follow-up, despite expert pharmacotherapy and psychotherapy. ${ }^{11}$ Aimed at shedding light on the matter, a set of 12 useful criteria has been proposed for a rational polypharmacy, essentially focusing on pharmacokinetic and pharmacodynamics issues, ${ }^{5}$ as previously done by other authors comparing different phases of BD. ${ }^{12}$ Yet, it has not been investigated which bipolar patients were most exposed to polypharmacy. There is clinically sound predictive value for a past history of treatment. This is seen in cases that include resistant bipolar depression, sub- or full-threshold mixed features, rapid-cycling course, or affective temperaments (especially cyclothymic one). They represent a few potential clinical moderators of "hard-to-catch" issues for standard treatment of guidelines for BD. ${ }^{13,14}$ Standard treatment guidelines on BD pose little or no attention overall toward the matter of polypharmacy, especially in relationship to the past history of treatment, which includes resistant bipolar depression, sub- or fullthreshold-mixed features, rapid-cycling course, or affective temperaments (especially cyclothymic one), despite their clinically sound predictive value overall. ${ }^{13,14}$ Both evidence in support of ${ }^{4,15,16}$ and in dispute against ${ }^{17-19}$ the practice of polypharmacy have been advocated to date. However, data about the actual prevalence and clinical correlates of the practice beyond the essential pharmacological and neurobiological premises are limited.

Therefore, we conducted a systematic review to assess the prevalence rates and clinical correlates across varying definitions of polypharmacy and varying mood phases of adulthood BD.

\section{Materials and methods}

This systematic review adhered to the Preferred Reporting Items for Systematic reviews and Meta-Analyses (PRISMA) (http://www.prisma-statement.org//20 following a registered publically available protocol (PROSPERO number: CRD42014015084).

\section{Eligibility criteria}

We limited our search to those records including adult subjects with $\mathrm{BD}$, published in peer-reviewed journals. Limits activated were species: humans, language: English, and all adult: $19+$, with no publication date restriction.

\section{Information sources and search strategy}

Sources of information included the following databases last accessed on September 11, 2015: PubMed/MEDLINE, Scopus, PsycINFO, EMBASE, Cochrane library, and Google Scholar. Contact with study authors was planned in advance whenever needed. The following keywords or their combination were used in the search strategy: "Bipolar Disorder" AND "polypharmacy" either in the title or in the abstract (or in the keywords, if allowed to be specified). Therefore, the adopted PubMed string was "Bipolar Disorder AND polypharmacy" (any field). Finally, the terms "polypharmacy," "polypharmacotherapy," "polypharmacology," "polytherapy," and "copharmacy" were used interchangeably across multiple databases.

\section{Study selection}

Included papers were those reporting epidemiological data about the prevalence and clinical features associated with polypharmacy in course of BD, with no restriction on etiology, bipolar type, specifiers/features, phase of illness or pharmacological and/or nonpharmacological treatment, class, dose, or duration of the pharmacological trials. Papers covering cases of polypharmacy in $\mathrm{BD}$ comorbid with additional disorders (either psychiatric or medical disorders/diseases) were also accounted whenever available. When a title and/or an abstract appeared suggestive for inclusion, the full-text reprint was obtained and examined to assess its relevance according to our inclusion/exclusion criteria. Excluded papers were case reports, oral communications, papers not including BD cases (multidiagnostic samples were nonetheless allowed) receiving multiple psychopharmacological treatments at once (any indication), those merely focusing on neurobiological, genetic, or pharmacological aspects of either BD or polypharmacy, those including (only) children or adolescents, or without an accurate description of the operative constructs of polypharmacy. 


\section{Data collection process}

Three authors (MF, BS, and DV) conducted a two-step literature search, examining all titles and abstracts, accessing the full texts of potentially relevant papers. On data collection and extraction, the appointed authors compared their own results with each other to reach a final consensus based on consensual inclusion and exclusion criteria. Any possible discrepancy between the principal investigators, blind to each other, was solved by consultation with three reviewing authors (ASK, DDB, and GP). Both autosearch and hand search for "type I" (duplicates among/across different databases) and "type II" (duplicate publications in different Journals/issues) ${ }^{21}$ were performed using Thomson Reuters EndNote X7 $7^{\mathrm{TM}}$ for Microsoft Windows ${ }^{\mathrm{TM}}$. Data were screened for the following characteristics: Participants, Interventions, Comparisons, Outcomes, and Study Design (PICOS) as well as funding sources. Specifically, the recorded variables for each article included in the review were author(s), year publication, study design, sample size, eventual follow-up or control group, sociodemographic status, concurrent psychotherapy or history of physical treatment for BD, outcome measures, conclusions, limitations, quality score, and quality differentiation.

\section{Risk of bias in individual studies}

Potential major confounding biases in the studies have been ascertained at study level focusing on the following: measurement/diagnostic bias (especially inconsistent/ unreliable definitions of polypharmacy and/or lack of reliable diagnostic tools to make the diagnosis of $\mathrm{BD}$ ), confounding bias (eg, lack of stratification and multivariate control for specific sociodemographic, vital, or clinical features), information (especially recall) bias, unrepresentativeness or inhomogeneity of the sample size or lack of control group, and selection by indication bias (nonrandom assignment of the exposure where applicable). ${ }^{22}$

\section{Summary measures}

Summary measures were risk ratio for cohort studies, odds ratio (OR) for case-control studies, or difference in mean values. Cohen's $d$ effect sizes were reported, whenever available or anyway ascertainable.

\section{Scoring and ranking of the studies}

The assessed studies were rated for quality using the following eligibility criteria: 1) representativeness of the sample ( $0-1$ point $) ; 2)$ presence of $\mathrm{BD}$ patients only in the sample (0-2 points); 3 ) a priori study design with the goal of evaluating the epidemiology of polypharmacy in $\mathrm{BD}$ (0-2 points); 4) extension of the follow-up (longitudinal studies)/clinical records (retrospective studies) $>1$ year (0-2 points); 5) validation of the clinical diagnosis and definition of polypharmacy and the used treatment (if applicable) (0-2 points); 6) inclusion and control of all the available variables for potential confounders/effect modifiers that may had influenced outcome (if applicable) (0-2 points); 7) reliability of the information gathered for the identification of BD cases/recall bias ( $0-2$ points); 8) accuracy of the study was to discern between manic, hypomanic, mixed, and depressive episodes in BD (0-2 points); and 9) appropriateness of the number of comorbid cases reported as results/sample size (0-2 points). Quality rating had 17 as the maximum score.

Studies were also differentiated in the following way: 1) good quality: most or all criteria being fulfilled, and even when they were not met, the study conclusions were thought to be very unlikely to alter (range: 10-17 points); 2) moderate quality: some criteria being fulfilled, and when they were not met, the study conclusions were thought to be unlikely to alter (range: 6-9 points); and 3) poor quality: few criteria fulfilled but the conclusions of the study were thought to be very likely to alter (range: $0-5$ points).

\section{Main clinical features at study}

Among others, the following effect moderators were accounted for in the analysis: 1) illness duration; 2) ethnicity (in order to explore whether ethnic minorities may receive different care); 3) any kind of socioeconomic measure or a proxy for that, for example, education status; 4) a baseline psychiatric symptoms/general functioning score; 5) physical comorbidity; 6) psychiatric comorbidity; 7) differences in setting; 8) year of data collection (to reflect the time frame of introduction of different drugs, especially atypical antipsychotics); 9) geographical region; and 10) study design and duration of follow-up (taking into account that cross-sectional studies and those with shorter follow-up may have higher rates of polypharmacy, as it could be either part of cross-titration or transient).

\section{Risk of bias across the studies}

Any eventual bias affecting cumulative evidence (eg, publication bias, selective reporting within studies) was assessed through the study evaluation process and accounted in the discussion of the present manuscript. 


\section{Results}

\section{Study selection}

The search in PubMed generated 112 papers and 320 results in Scopus. Four hundred eleven additional results were obtained through search in Cochrane $(n=7)$, PsycINFO $(n=1)$, EMBASE $(n=361)$, or Google Scholar $(n=19$ - including six edited books - out of 8,070 results initially obtained before limiting the Google Scholar search strategy to title and abstract, excluding patents or citations). Manual search allowed the identification of 23 additional results. Overall, the combined search strategy yielded a total of 843 results, of which 414 were removed after screening because they duplicated other articles. Three hundred eleven results were further screened; of those latter, 72 were excluded because they were not fully meeting the planned inclusion criteria (with a special reference to the operative definition of polypharmacy and the number of bipolar patients included). Therefore, 31 original studies were included in our qualitative analysis. ${ }^{3,23-51}$ Figure 1 provides a synthetic flowchart of the multistep selection procedure. Overall, the combined search strategy yielded 843 results. Following screening for duplication, 414 articles were selected. On further evaluation, 311 studies were eliminated leaving 103 full-text articles. In all, 72 such articles were then excluded as they did not meet the planned inclusion criteria (especially, the operative definition of polypharmacy and the number of bipolar patients were included). Therefore, 31 original studies were included in our qualitative analysis. ${ }^{3,23-51}$ Figure 1 provides a synthetic flowchart of a multistep selection procedure.

\section{Quality score and quality differentiation results}

Based on the quality differentiation, original studies were ranked as follows: poor $(n=7$, mean total score $=3.5)$, moderate $(n=13$, mean total score $=8.2)$, or good quality $(\mathrm{n}=11$, mean total score $=12.8)$. Additional details about pivotal cross-sectional, retrospective, and longitudinal studies have been outlined in Tables $1-3$, respectively.

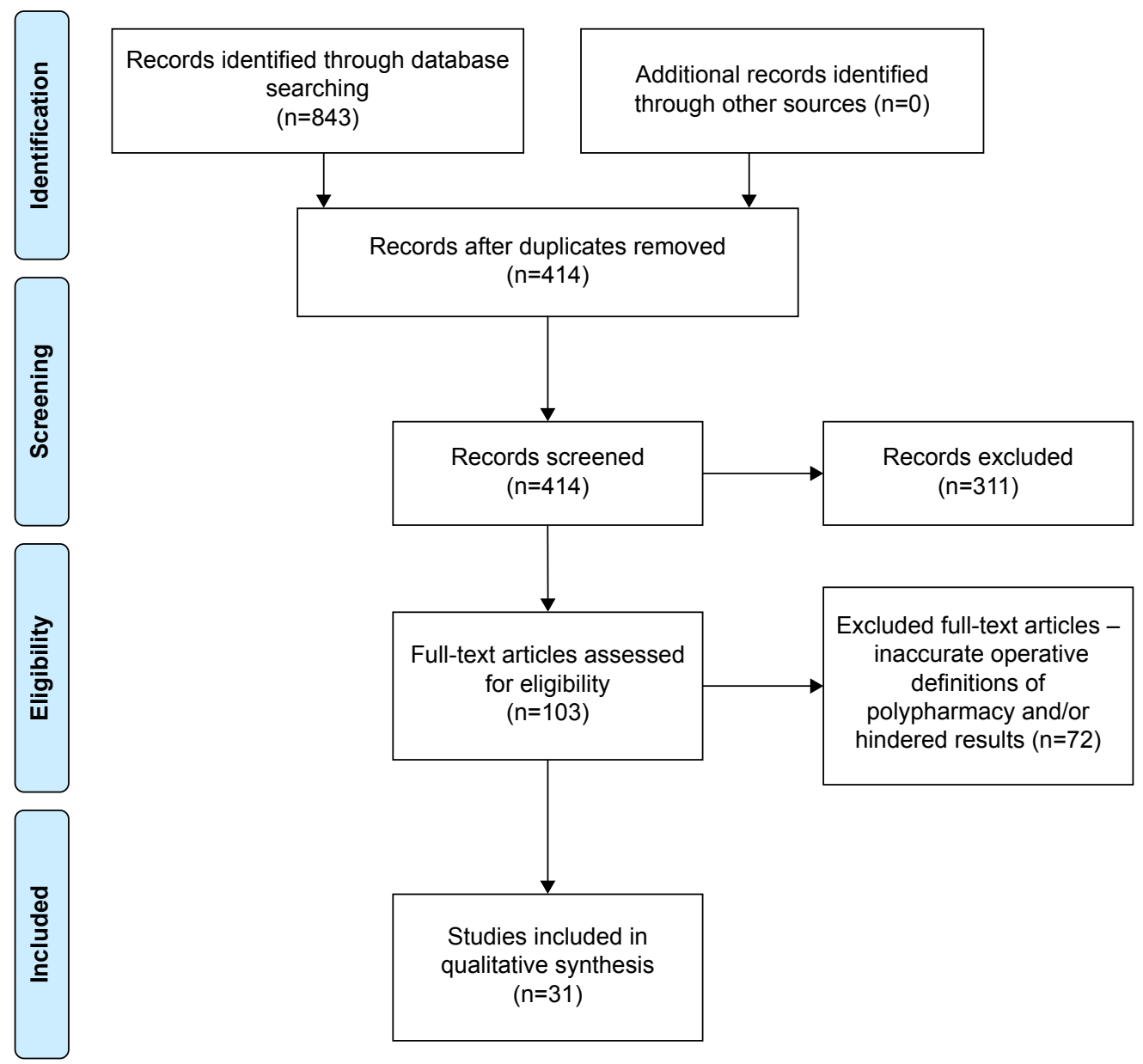

Figure I Adapted PRISMA 2009 flow diagram. 

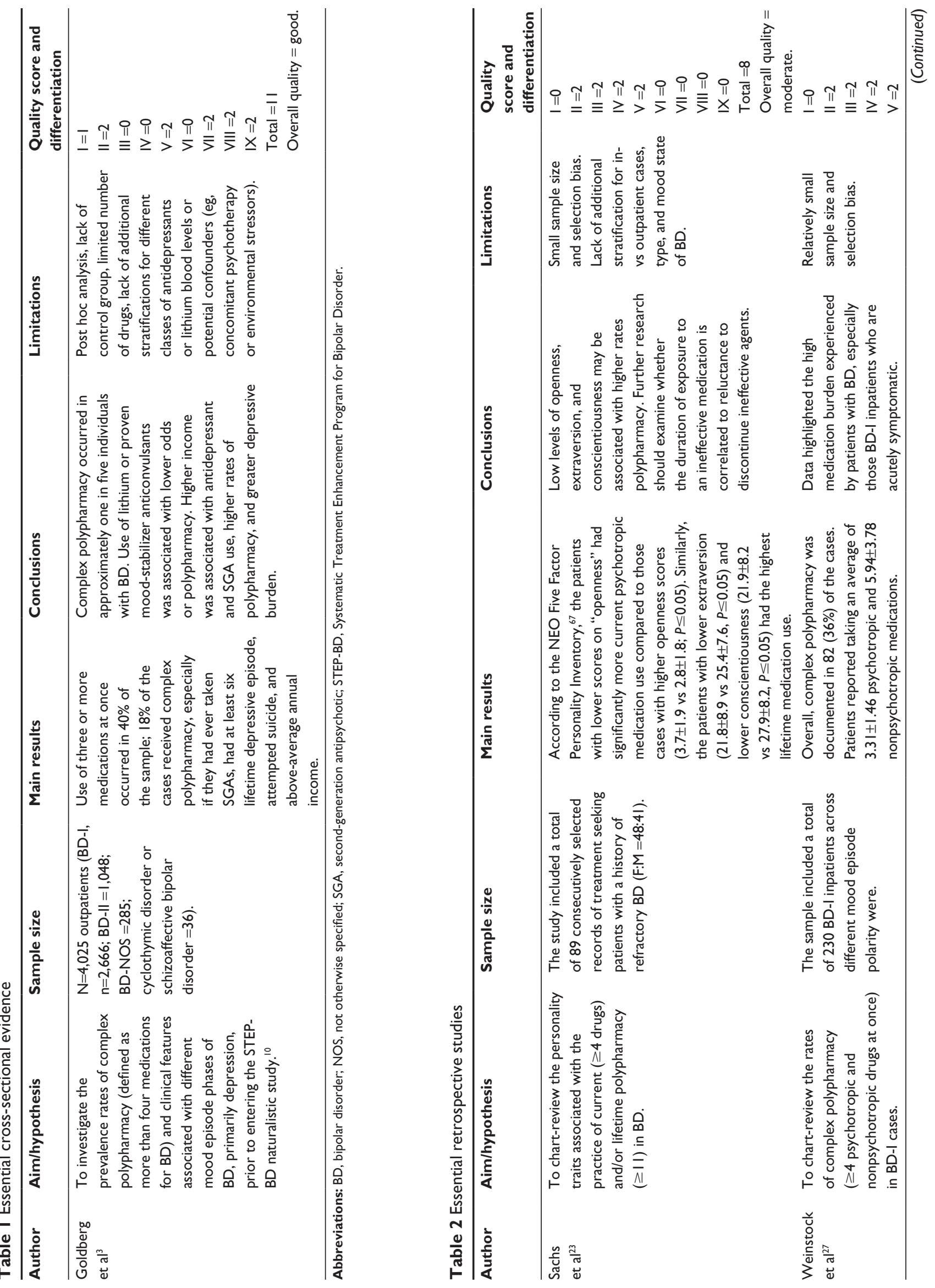


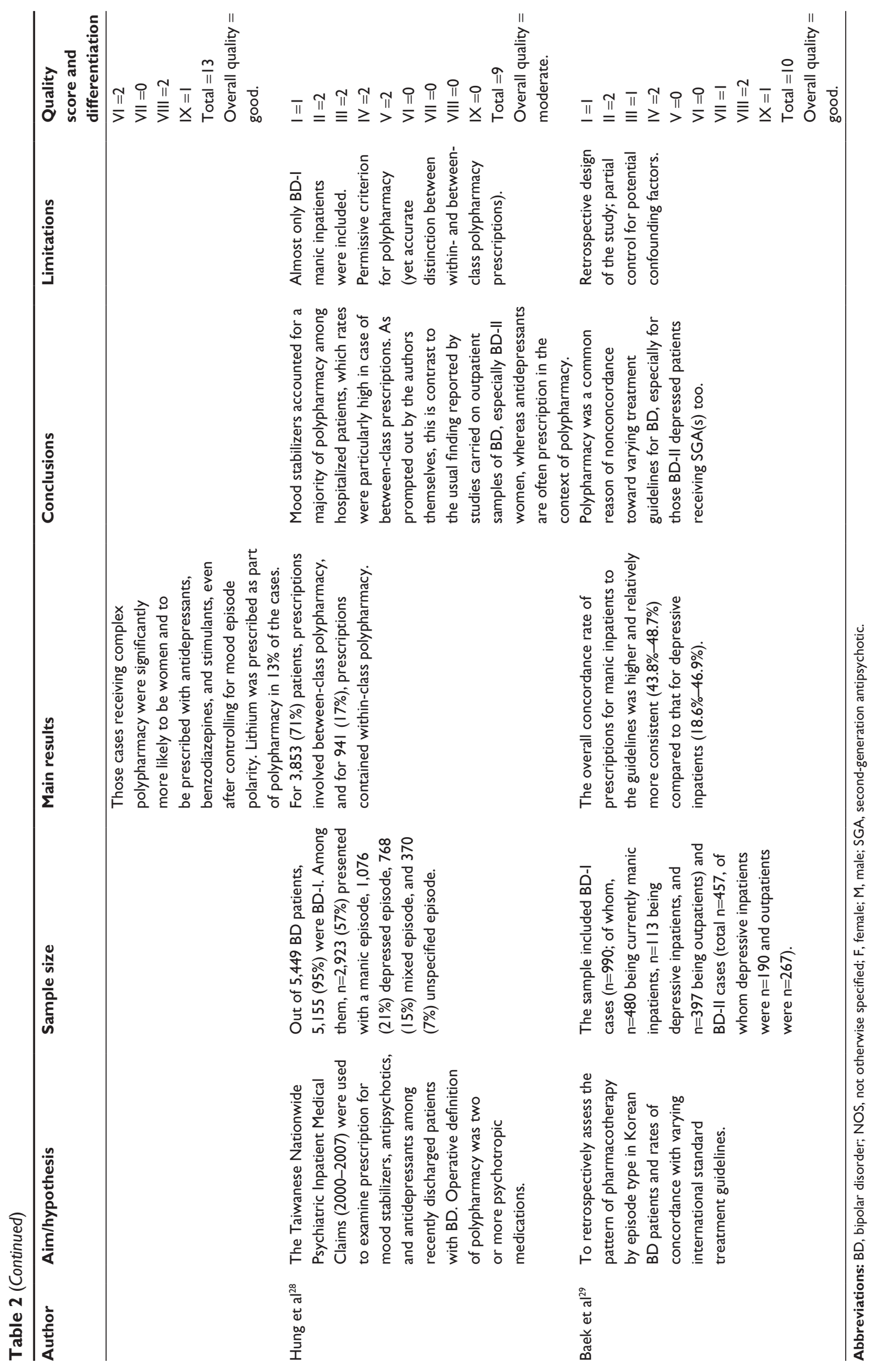




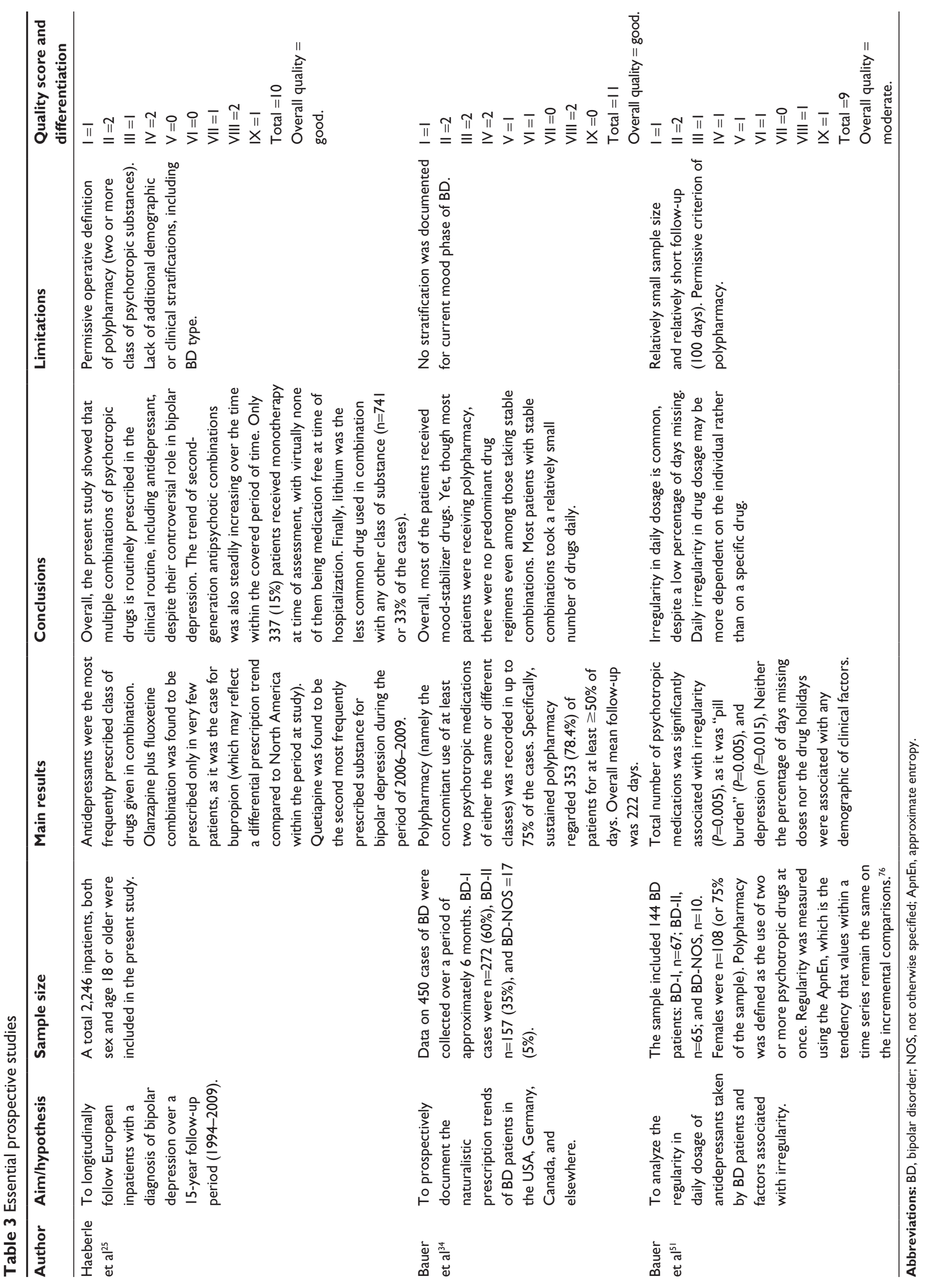




\section{Conceptual and operative definitions of polypharmacy across selected studies}

Polypharmacy has been defined in at least 24 distinct conceptual ways, with "medication nonmatching a diagnosis" being the most commonly adopted conceptual definition, ${ }^{52}$ capturing what could be both inappropriate therapy, that is, too many medications, and "evidence-based therapy that is inappropriate." ${ }^{153}$ The operative definitions of polypharmacy are also elusive and/or too broad, ${ }^{54-56}$ with the most commonly used definitions of psychiatric polypharmacy being the "use of two or more psychiatric medications in the same patient," ", 55 rather than "use of two or more medications of the same class or equivalent pharmacologic action to treat the same condition [BD]." ${ }^{57}$ Nonetheless, "current use of four more psychotropic medications at once" was the most reliable operative definition for "complex polypharmacy" across the most pivotal studies. $3,23,27,40,42$

\section{Prevalence rates of polypharmacy in $\mathrm{BD}$}

A post hoc ${ }^{3}$ report based on the baseline data of the STEP-BD study $^{10}$ indicated that only $12 \%$ of the patients ( $\mathrm{n}=472$ out $4,035)$ were taking none of the accounted medication at study entry, in contrast to 839 (21\%) taking one vs 1,130 (28\%) receiving two medications vs $883(22 \%)$ on three vs 711 (18\%) taking four or more medications (complex polypharmacy). Of 2,159 females (53.5\% of the total sample), $21 \%$ of whom $(n=446)$ were received complex polypharmacy. With respect to the diagnostic type of $\mathrm{BD}, 2,666$ patients were BD-I, of whom, 510 received complex polypharmacy, 2,156 received less than four medications; 1,084 were BD-II (complex polypharmacy, $n=171$ vs 913 not receiving complex polypharmacy); and $285 \mathrm{BD}$-not otherwise specified (NOS) cases, of whom just 30 received complex polypharmacy vs 255 who did not.

The operative definition of complex polypharmacy adopted for the STEP-BD post hoc ${ }^{3}$ was modified by independent authors conducting a chart-review study on 230 BD-I patients (of whom, 134 or $58 \%$ females) admitted to an inpatient or partial hospitalization, herein encompassing all classes of psychotropic and nonpsychotropic medications in order to better reflect routine clinical prescriptions for BD patients..$^{27}$ In all, 186 of the cases ( $81 \%$ of the total sample) received complex polypharmacy, while 122 (53\%) reported taking medication for nonpsychiatric purposes. Polarity of mood episode on admission was as follows: depressed, $n=85$ (37\%); manic, $n=96$ (42\%); mixed state, $\mathrm{n}=44(19 \%)$; and unspecified, $\mathrm{n}=5$ (2\%). Among those treated with pharmacotherapy for $\mathrm{BD}$, patients reported taking an average of $3.31 \pm 1.46$ psychotropic medications at the time of hospitalization. Average total medication usage (including both psychotropic and nonpsychotropic medications) was $5.94 \pm 3.78$. One hundred twenty-six cases $(55 \%$ of the sample) reported taking three or more psychotropic medications at the time of hospitalization, and 82 cases (36\%) of the study met the operational criteria for complex polypharmacy. This figure represents $44 \%$ of those receiving any pharmacotherapy for BD at the time of hospital admission. Overall, even after accounting for $20 \%$ of patients who were not engaged in any pharmacologic treatment prior to hospitalization, 55\% were on three or more psychotropic medications at the time of hospital admission and $36 \%$ were on four or more. The latter figure is exactly double than the rate reported from the outpatient STEP-BD sample, ${ }^{3}$ although more consistent with rates of polypharmacy reported in voluntary BD registries ${ }^{41}$ Concordant with previous reports, ${ }^{58,59}$ additional analyses carried out by Weinstock et $\mathrm{al}^{27}$ revealed that the average number of prescriptions almost doubled (from 3.3 to 5.9) when both psychotropic and nonpsychotropic medications were taken into account. The authors themselves also acknowledged that the discrepancy seen with respect to the STEP-BD post hoc report ${ }^{3}$ may be attributable to different operational criteria for complex polypharmacy, differential settings, and proportion of BD-I cases.

Data from the Arzneimittelüberwachung in der Psychiatrie (AMSP) European drug surveillance program ${ }^{60,61}$ involving 2,246 cases of bipolar depression followed over a 16-year period (1994-2009) 25 just relied on a "permissive" operative definition of polypharmacy, namely the use of two or more class of psychotropic substances. The prevalence rates of polypharmacy in European patients were therefore strikingly high, with almost $85 \%$ of the cases receiving polypharmacy in contrast to only 337 cases (or $15 \%$ of the total) receiving monotherapy (herein defined as the use of antidepressants or antipsychotics or anticonvulsants or lithium, including within-class prescriptions). Data about the practice of complex polypharmacy in European cases experiencing a current bipolar depressive episode were nonetheless made available by a 2012 report based on 2,231 inpatients (unspecified subtypes proportions) followed up in the context of the AMSP program between 1994 and 2009, which documented 137 patients $(6.4 \%$ of the total) treated with at least four different psychotropic drugs at once, with rates steadily increasing, especially after year 2006. ${ }^{33}$ Data about the practice of polypharmacy in Eastern European and Middle East patients just rely on post hoc cross-sectional analysis of the baseline records of a large $(\mathrm{n}=894)$ prospective 
study carried on manic patients prescribed with olanzapine $(n=569$ or $63.64 \%)$ or not $(n=325$ or $36.35 \%)$. While these data reflect a special population at study, the rates of polypharmacy were nonetheless very high ( $n=719$ or $80.4 \%$ ), although the authors adopted a permissive criterion of two or more psychotropic drugs at once. ${ }^{31}$ Slightly lower prevalence rates in manic patients were also documented in Taiwanese inpatients approximately assessed within the same period (years 2000-2007). Specifically, out of 5,449 BD patients, 5,155 (95\%) were BD-I cases, of whom 2,923 (57\%) presenting with a manic episode at the time of hospitalization, 1,076 (21\%) with depressed episode, 768 (15\%) mixed episode, and $370(7 \%)$ unspecified episode. Between-class vs withinclass polypharmacy (according to the permissive criterion of two or more psychotropic drugs at once) occurred in 3,853 (71\%) vs 941 (17\%) patients, respectively. ${ }^{28}$

\section{Prescription trends and main clinical features associated with polypharmacy in $B D$}

Quality receiver-operating characteristics post hoc analysis of the baseline records of the STEP-BD study ${ }^{3}$ also revealed that $\mathrm{BD}$ subjects had a $64 \%$ risk for receiving complex polypharmacy if they had ever taken any second-generation antipsychotic (SGA) drug, had six or more lifetime depressive episodes, ever attempted suicide (complex polypharmacy cases, $\mathrm{n}=686$, vs noncomplex polypharmacy cases, $\mathrm{n}=1,105 ; P \leq 0.0001$; Cohen's $d=0.05$ ), and had an annual income of US\$75,000 or higher (complex polypharmacy cases, $n=158$, vs noncomplex polypharmacy cases, $n=747$; $P=$ nonsignificant $[\mathrm{ns}] ; d=0.00)$. In contrast, complex polypharmacy was least often associated with lithium ( $n=41$ vs 225 receiving lithium but not complex polypharmacy; $d=0.03$ ), divalproex (251 vs 934 noncomplex polypharmacy cases; $d=0.11$ ), and carbamazepine ( 219 vs $n=548$ noncomplex polypharmacy cases; $d=0.13$ ), whereas complex polypharmacy was most often associated with SGA use (complex polypharmacy cases, $n=482$, vs noncomplex polypharmacy cases, $n=780 ; d=0.74$ ), with antidepressants ( 684 vs $n=1,251$ noncomplex polypharmacy cases; $d=0.78$ - which is actually the largest effect size reported by the authors in their analyses). Contrary to expectations, a history of psychosis (complex polypharmacy cases, $\mathrm{n}=96$, vs noncomplex polypharmacy, $\mathrm{n}=309 ; P=0.001 ; d=0.02$ ), age at onset (complex polypharmacy mean age $=16.4 \pm 3.3$ vs noncomplex polypharmacy mean age of onset of $16.2 \pm 3.6 ; P=\mathrm{ns} ; d=0.03$ ), BD-I vs BD-II subtype (no contrasts, $P$-value or $d$ value reported), prior to hospitalization (no contrasts, $P$-value or $d$ value reported), current illness state (no contrasts, $P$-value or $d$ value reported), and history of substance use disorder (SUD) (complex polypharmacy, $\mathrm{n}=84$, vs noncomplex polypharmacy, $\mathrm{n}=461 ; P=\mathrm{ns} ; d=0.05)$ did not significantly alter the risk profiles for receiving complex regimens, although concerns about the chance of a Berkson's bias could be raised in these regards. Accounting of additional psychotropic and nonpsychotropic medications beyond the sole, seven-core medications regarded by the STEP-BD study (namely lithium, divalproex, carbamazepine, lamotrigine, and other anticonvulsants without definitely established thymoleptic properties as topiramate, gabapentin; oxcarbazepine, as well as SGA or any antidepressant) allowed Weinstock et al to provide additional insights about the clinical correlates of complex polypharmacy in $\mathrm{BD} .{ }^{27}$ Overall, according to this latter report, those BD-I cases receiving complex polypharmacy were significantly more likely to be female, depressed, have a comorbid anxiety disorder, and have a history of suicide attempt. Conversely, those receiving complex polypharmacy were significantly less likely to be manic and present with active psychosis at the time of hospital admission. Noteworthy, given that medication decisions may be especially driven by mood episode polarity, the authors decided on a priori basis to treat mood episode polarity as a covariate in any multivariate analysis to evaluate the demographic and clinical factors associated with complex polypharmacy and patterns of specific medication use, over and above any shared variance with mood episode. Therefore, controlling for mood episode polarity, female sex, $B$ (standard error $[\mathrm{SE}])=0.58(0.29), \chi^{2}(1)=3.88, P=0.049$, OR $=1.78$; anxiety disorder comorbidity, $B(\mathrm{SE})=0.72(0.32), \chi^{2}(1)=5.18$, $P=0.023, \mathrm{OR}=2.05$; and history of suicide attempt, $B(\mathrm{SE})=0.79(0.34), \chi^{2}(1)=5.60, P=0.018, \mathrm{OR}=2.21$ remained significant predictors of complex polypharmacy for BD-I, whereas psychosis did not, $B(\mathrm{SE})=-0.50(0.32), \chi^{2}(1)=2.40$, $P=0.121, \mathrm{OR}=0.61$. Each psychotropic medication class was significantly associated with increased likelihood of complex polypharmacy. With respect to pattern of medication use by mood episode polarity, there was no statistically significant difference between depressed and mixed polarity patients (all $P=0.11-0.94$ ). As such, the authors combined these latter groups for purposes of comparison against patients presenting with pure mania. Use of antidepressants was significantly higher in the depressed/mixed polarity patients in comparison to patients presenting with pure mania (45\% vs $20 \%$; $\left.\chi^{2}(1)=15.49, P<0.001\right)$. This pattern of effects held for the use of selective serotonin reuptake inhibitors (26\% vs $12 \%$; $\left.\chi^{2}(1)=7.64, P=0.006\right)$, serotonin norepinephrine reuptake 
inhibitors $\left(10 \%\right.$ vs $\left.2 \% ; \chi^{2}(1)=5.65, P=0.017\right)$, and all other antidepressants $\left(19 \%\right.$ vs $\left.7 \% ; \chi^{2}(1)=5.93, P=0.015\right)$. Use of benzodiazepines (BDZs) was also significantly higher in the depressed/mixed polarity patients vs those presenting with mania ( $47 \%$ vs $\left.33 \% ; \chi^{2}(1)=4.42, P=0.036\right)$, while use of all remaining medications (ie, lithium, anticonvulsants, antipsychotics, stimulants, and hypnotics) did not differ as a function of episode polarity (all $P$-values $=0.08-0.90$ ). In addition, corresponding information about the use of varying classes of antidepressants for European BD inpatients receiving polypharmacy (yet herein adopting a permissive criterion of two or more drugs within different classes at once) was provided by Haeberle et al in $2012 .{ }^{25}$ Olanzapine plus fluoxetine combination was found to be prescribed only in very few patients, as it was the case for the norepinephrine dopamine reuptake inhibitor bupropion, also possibly due to different drug policies and approval dates compared to the USA, despite the SGA quetiapine was found to be the second most frequently prescribed adjunctive therapy for bipolar depression during the period covered by the study, years 2006-2009, whereas lithium was the less common drug used in combination with any other class of substance $(n=741$ or $33 \%$ of the cases). ${ }^{25}$ Owing to evidence pointing out that less than one-third of BD patients in the USA and about half of those in Europe received monotherapy, ${ }^{3,62-65}$ Bauer et al planned a long-term naturalistic study in which patients with BD self-recorded mood, sleep, and drugs taken daily over a period of $\sim 6$ months with the ultimate aim to further characterize the drug treatment patterns in $450 \mathrm{BD}$ cases. Of these latter BD cases, 272 were BD-I cases (60\%), 157 BD-II (35\%), and 17 BD-NOS cases (5\%). Noteworthy, the study adopted a permissive operative criterion for polypharmacy defined as the use of two or more psychotropic drugs at once. ${ }^{34}$ Drug load was measured using the methodology developed by the World Health Organization (WHO) based on a measure of equipotency known as the defined daily dose ${ }^{66}$ Overall, 315 or $70 \%$ of the cases resided in the USA; $\mathrm{n}=53$ or $11.8 \%$ resided in Germany; $\mathrm{n}=45$ or $10 \%$ resided in Canada; and 37 or $8.2 \%$ resided elsewhere. Enrolled patients returned a total of 99,895 days of data (mean 222.0 days), with the most frequently taken drugs being mood stabilizers and 353 patients (78.4\% of the total) taking a stable drug combination for half of days or longer. The majority of patients were taking polypharmacy, including $75 \%$ of those with a stable combination. Only a small number of drugs were commonly taken within each medication class, but there were a large number of unique drug combinations: 52 by medication class and 231 by specific drugs. Eighty percentage of patients with a stable combination were taking three or less drugs daily, although no specific report was documented in relationship with polypharmacy and lifetime hospitalization. Two previous chart-review studies on 457 BD-I cases suggested a positive correlation between the total number of current psychotropic medications and the number of hospitalization for depressive episodes, though not with suicidal attempt, neither lithium nor carbamazepine use in case of hospitalization due to mania. ${ }^{40,41}$ Finally, while most crosssectional and longitudinal studies on the relationship between polypharmacy and the clinical features and/or prescription trends primarily focused on symptomatic cases of BD, evidence focusing just on 80 euthymic patients documented that those subjects self-reporting normal mood over a period of 3 consecutive months or longer usually received a lower number of drugs compared to nonlasting cases of euthymia, though a "selection by indication bias" would be prompted out considering that those cases receiving polypharmacy may already include the most severe and possibly rapid-cycling course cases of BD. ${ }^{42}$

\section{Personality features associated with polypharmacy in $B D$}

A retrospective chart review of 89 treatment-seeking BD outpatients ( $\mathrm{F}: \mathrm{M}=48: 41$ ) assessed by the means of the revised NEO Five Factor Personality Inventory ${ }^{67}$ about five personality dimensions, including neuroticism (the tendency to experience negative affect), extraversion (a tendency toward energy, positive emotions, and stimulation-seeking), conscientiousness (a tendency toward self-discipline and dutiful behavior), openness to experience (sometimes described as intellectual curiosity), and agreeableness (a tendency to be cooperative and compassionate) took into account 41 commonly prescribed psychotropic medications grouped in six classes (mood stabilizers, antidepressants, dopamine blockers, anxiolytic/sedative hypnotics, stimulants, and other) splitting the samples based on mean psychotropic medication use as follows: for current psychotropic medications: $\leq 3=$ low vs $\geq 4=$ high and for lifetime medications: $\leq 10=$ low vs $\geq 11=$ high. The subgroup with low openness had significantly more current psychotropic medications $(3.7 \pm 1.9)$ than patients in the higher distribution of openness scores $(2.8 \pm 1.8, P<0.005)$. There was no other comparison that reached statistical significance for either current or lifetime medications. Nonetheless, the subgroup using 18 or more lifetime psychotropic medications had significantly lower extraversion $(21.8 \pm 8.9$ vs $25.4 \pm 7.6, P \leq 0.005)$ and lower conscientiousness $(21.9 \pm 8.2$ vs $27.9 \pm 8.2, P<0.001)$ 
than those reporting lifetime usage of fewer than controls. Remarkably, the authors did not examine whether the duration of exposure to an ineffective medication would be correlated to reluctance to discontinue the ineffective agent, so that at present, conclusive statement about the potential moderator effect of personality traits in $\mathrm{BD}$ as measured by the means of the NEO Five Factor Personality Inventory could not be drawn.

\section{Polypharmacy in suicidal behavior bipolar patients}

Although different studies also accounted for suicidal cases of $\mathrm{BD}$, the only quantitative evidence specifically addressing this issue involved 169 BD outpatients (most of whom being BD-I cases, $n=145$ or $85.7 \%$ ) and used a permissive criterion for polypharmacy (two or more psychotropic medications), which actually occurred in 142 (84\%) of the cases in contrast to just 27 patients $(16 \%)$ receiving monotherapy. Polypharmacy with three or more medications occurred in 31 (19\%) of the cases. Overall, rapid-cycling course was seen in up to $26.9 \%$ of the cases, which is a quite high rate, especially taking into account that most of the suicidal behavior outpatients were BD-I rather than BD-II cases.

\section{Antipsychotic drugs prescription rates and polypharmacy in BD}

The evidence about the use of antipsychotic polypharmacy in $\mathrm{BD}$ is also scarce and prone to publication bias considering the relatively novel introduction of most SGA drugs or their latter approval for BD and/or popularity as off-label prescriptions for BD patients, which nonetheless increased over the time. ${ }^{68}$ Also, different prescription trends for SGA vs firstgeneration antipsychotics (FGAs) may depend on the geographical setting and resource settings, as Eastern European BD inpatients were less frequently prescribed with SGAs in comparison to their Western counterpart, with a 2010 report documenting $23.8 \%$ of them receiving two antipsychotics vs $28.6 \%$ receiving "complex antipsychotic polypharmacy." 48 Indeed, much larger samples of BD patients prescribed with antipsychotic polypharmacy were documented by North American studies. For example, retrospective data on multistate Medicaid population for years 1998-2003 regarded 8,489 BD patients (unspecified proportion of BD subtypes), of whom $623(7.3 \%)$ took antipsychotic polypharmacy (one or more antipsychotic drug) for at least 60 consecutive months (accountable SGAs at the time were olanzapine, quetiapine, risperidone, and the atypical antipsychotic clozapine). ${ }^{44}$ Additionally, cross-sectional information on antipsychotic polypharmacy based on 1998 data (accounted
SGAs could be olanzapine, quetiapine, risperidone, or clozapine) about US inpatients with psychotic disorders, of whom 36 were diagnosed with BD (unspecified subtypes), documented equal rates of antipsychotic polypharmacy (two or more drugs), and antipsychotic monotherapy ( $n=18$ or $50 \%$ each group). It also documented the association of short-term treatment with multiple antipsychotics to major increase in drug exposure, adverse events, and time in the hospital, with no apparent gain in clinical benefit. ${ }^{46}$ An updated 2008 report by Centorrino et al still based on 2004 records of antipsychotic polypharmacy in US inpatients documented very high rates of polytherapy including one antipsychotic drug $(80 \%)$ or two or more antipsychotics $(23 \%)$ at once for at least 3 consecutive days in the BD subset of the sample wherein BD subjects formed ( $\mathrm{n}=37$ out of 305 or $12.13 \%$ ). Yet again, no clear-cut stratification between FGA and SGA was documented for, across varying BD subsets. ${ }^{45}$ Concerning the antipsychotic prescribing patterns in US outpatients, a chart review of 2003-2004 data using a permissive operative definition of two or more antipsychotics involving also BD cases ( $n=511$, no stratification of results across different BD subtypes) documented antipsychotic polypharmacy prevalence rates of 10\% (53 cases), with accounted SGAs being risperidone, olanzapine, and quetiapine, although once again results were not stratified distinguishing between FGA vs SGA prescription trends. ${ }^{47}$

\section{Polypharmacy in special BD populations}

Little is known about the practice of polypharmacy among special population of $\mathrm{BD}$, and virtually no data exist about any eventual difference in care based on ethnicity in non-US samples. Sometimes, rates have been documented in qualitative but not quantitative way, as it was the case of BD inpatients with SUD reported to receive both higher number and doses of both conventional mood stabilizers and SGAs compared to non-SUD lifetime comorbidity. ${ }^{69}$ Only a handful of studies have nonetheless provided essential quantitative data for alternative special settings/population of BD. Our knowledge is relatively limited even with respect to the practice of polypharmacy in BD inmates. Two longitudinal 12-week studies by Kamath et al documented strikingly high prevalence rates for polypharmacy (use of three or more psychotropic medications at one) in $84 \%$ of the cases (out of a total sample of $40 \mathrm{BD}-\mathrm{I}$ or BD-II cases, equal ratios for males and females) ${ }^{43}$ urging the need for standard medication algorithms to reduce the polypharmacy in the correctional setting, with a special reference to antidepressant and antipsychotic drugs. ${ }^{70}$ Similarly, despite the acknowledgment 
that pharmacological treatments for BD have historically been associated with neurocognitive side effects, especially in elderly subjects or otherwise possibly cognitively vulnerable subjects who would be particularly sensitive to polypharmacy, ${ }^{71,72}$ very little is known about these subjects, including bipolar subjects with intellectual disabilities (IDs). A report on $101 \mathrm{BD}$ patients $(\mathrm{F} / \mathrm{M}, \mathrm{n}=59 / 41)$ aged 60 and older (mean age: 68.9 \pm 7.8 years), of whom 57 (56\%) BD-I and 44 (44\%) BD-II cases, with an onset of first affective symptoms before age 50 in $75.6 \%$ cases, was nonetheless studied with respect to polypharmacy (two or more psychotropic medications), which was documented in $31.7 \%$ of the cases $(n=32)$, with equal daily median number of psychotropic medications in both BD-I and BD-II cases (median =2; interquartile range $=3$ ). Interestingly enough, among other classes of psychotropic drugs, lithium was the most frequently prescribed one in BD-I and BD-II cases: $63.2 \%$ vs $43.1 \%$, respectively. ${ }^{49}$ Regrettably, evidence about the practice of polypharmacy in BD outpatients with ID is even less conclusive, with the only available quantitative reports on the matter failing to provide any accurate stratification of results beyond the generic statement of similar polypharmacy rates occurring in ID $(n=59)$ and non-ID $(n=16)$ cases (range: $24 \%-38 \%$ ) based on the operative criterion of two or more drugs rates in the ID $(n=59)^{50}$ or relying on unrepresentative subsets of BD cases, ${ }^{73}$ despite the widespread and controversial clinical use of polypharmacy even for BD subjects with ID. ${ }^{74}$ Similarly, only one study about the practice of polypharmacy involving pregnant bipolar women could meet our inclusion criteria. ${ }^{32}$ Complete retrospective data $\sim 115$ pregnancies, 75 of whom were followed throughout gestation while 40 had data for one certain gestational period, based on the Medicaid database of 5,000 women coded according to the International Classification of Diseases, Ninth Revision within years 2002-2004 indicated that the mean number of medications taken during pregnancy for manic BD-I cases was three (range: $0-10$; mode $=3$ ), whereas $26.8 \%$ of the pregnant women filled prescriptions for six to ten medications during their pregnancy. Surprisingly, no dose change was made for the prescribed medications to accommodate changing metabolism across pregnancy. The most frequently prescribed psychotropic medications were from the opiate family, most likely due to comorbid diagnoses (especially SUD). However, the effects of taking multiple medications on pregnancy outcome and fetal development were unknown. ${ }^{32}$ These findings are nonetheless compelling, especially considering that according to the clinical records of 53 fertile women with different mental illnesses (including 24 BD cases), about one-third ( $\mathrm{n}=8$ or $36 \%$ ) were taking more than one psychotropic medication within the first trimester of an unplanned pregnancy. ${ }^{75}$

\section{Polypharmacy and treatment adherence in $B D$}

The association between polypharmacy (two or more psychotropic medications at once) and self-reported adherence with daily dose of mood stabilizer (lithium, valproate, lamotrigine, carbamazepine, or oxcarbazepine) was obtained by Bauer et $\mathrm{al}^{35}$ for 312 BD patients (BD-I, $\mathrm{n}=198$; BD-II =100; and BD-NOS $=14$ ) over a 6 -month period, accounting for the mean daily number of psychotropic drugs, which was $3.1 \pm 1.6$ ( $7.0 \pm 4.2$ pills daily). No significant association was found between the daily number of medications and the daily number of pills, although the smaller the dosage of mood stabilizer taken, the higher the self-reported adherence to overall psychotropic prescriptions. ${ }^{35}$ In order to further characterize the factors associated with irregularity of daily dosage of antidepressants in BD, Bauer et al gathered selfreported information about medication dosage and mood ratings from $144 \mathrm{BD}$ patients $(\mathrm{BD}-\mathrm{I}, \mathrm{n}=67$ or $47.2 \%$; BD-II, $\mathrm{n}=65$ or $45.8 \%$; and BD-NOS, $\mathrm{n}=10$ or $7 \%$ ) who received treatment as usual (of whom, 111 were also taking a mood stabilizer). ${ }^{51}$ Regularity was measured using the "approximate entropy" (ApnEn), which is the tendency that values within a time series and remains the same on incremental comparisons. ${ }^{76}$ The authors documented that although the mean percentage of days with missing doses was only $18.6 \%$, there was a wide range of regularity in the daily antidepressant dosage. Drug holiday and polypharmacy (namely the use of two or more psychotropic drugs) were also significantly associated with irregularity $(P=0.005)$, as it was the case for "pill burden" $(P=0.005)$, and depression $(P=0.015)$. Neither the percentage of days missing doses nor the drug holidays were associated with any demographic or clinical factors in the sample at study, which predominantly included female cases over male ones ( $\mathrm{F}: \mathrm{M}, \mathrm{n}=108: 36$ or $75 \%$ vs $25 \%$ ). Interestingly enough, the authors concluded that irregularity in daily dosage may be more dependent on the individual rather than on a specific drug, despite there being no assessment of temperamental or personality traits of the involved patients over the 100-day follow-up period. Nonetheless, conclusive evidence about the association of treatment nonadherence and polypharmacy in BD remains elusive, as a 2008 report by Baldessarini et al indicated that prevalent lack of treatment at 1 year was associated with sustained mood-stabilizer adherence (subgroup, $n=620$ ), with those 
patients on lithium or lamotrigine being more often adherent than those prescribed with valproate, carbamazepine, or oxcarbazepine (nonadherent subgroup, $\mathrm{n}=1,577$; uncertain cases were excluded in secondary analyses).

\section{Polypharmacy rates and concordance with standard treatment guidelines in BD}

Polypharmacy accounted for nonconcordance with varying different guidelines for the pharmacological management of $\mathrm{BD}$ as documented by a Korean chart review using the permissive operative criterion of two or more psychotropic medications at once. ${ }^{29}$ The study included 1,447 BD patients, including 990 BD-I cases (of whom, $n=480$ being currently manic inpatients; $n=113$ being depressive inpatients; and $\mathrm{n}=397$ being outpatients) and 457 BD-II patients (of whom, $\mathrm{n}=190$ being depressive inpatients and $\mathrm{n}=267$ being outpatients. The authors concluded that varying degree of concordance rates across different guidelines essentially depended on the structure of heterogeneous guidelines themselves. For example, the 2009 edition of the Canadian Network for Mood and Anxiety Treatments (CANMAT) 77 and 2010 of the Korean Algorithm for Bipolar Disorder (KMAP-BP) guidelines had identical initial strategy for mania. In the manic inpatient group, the initial treatment strategy for 317 (66.0\%) of 480 patients was equally concordant with both these latter guidelines. Nonconcordant initial treatment strategies included SGA polypharmacy (22.1\%), mood-stabilizer polytherapy (9.6\%), and use of carbamazepine (1.9\%) or typical antipsychotics $(0.4 \%)$. Approximately half of concordant cases at the initial step had continued the same strategy for the entire treatment period (176 of 317, 55.5\%). The concordance rate was lower for the next step in the treatment. The overall concordance rate with the CANMAT guidelines was $48.7 \%$ (234 of 480), and the concordance rate with the KMAP-BP guidelines was $43.8 \%$ ( 210 of 480 ). Mean duration to proceed to the next treatment step (adding or discontinuing medication) was $\sim 15$ days. In addition, the CANMAT guidelines provide an algorithm among bipolar depression only for bipolar I disorder $(\mathrm{n}=113)$. In the depressive inpatient group, only 30 cases $(26.5 \%)$ were concordant with the initial treatment strategy of the CANMAT guidelines. More than half of the subjects were treated with the combination treatment, which was not included in the first step of the CANMAT algorithm. The overall concordance rate with the CANMAT guidelines was only $18.6 \%$ (21 of 113). Most nonconcordant subjects started two or more different medications concomitantly. The concordant rate for bipolar depression with the initial strategy of the KMAP-BP guidelines was 63.4\% (192 of
303), as KMAP-BP included mood stabilizer plus SGA as one of the first options for bipolar depression. Nonconcordant initial treatment strategies essentially regarded SGA polytherapy and multiple mood stabilizers at once. The overall concordance rate with the KMAP-BP guidelines was $46.9 \%$ (142 of 303). When compared the concordance rate with the 2006 edition of the American Psychiatric Association (APA) practice guidelines ${ }^{78}$ and the 2009 edition of the World Federation Societies for Biological Psychiatry (WFSBP) guidelines,${ }^{79}$ the overall concordance rates for mania were only $7.3 \%$ and $2.1 \%$, respectively. The authors concluded that nonconcordance occurred mainly because lithium is not recommended as the first line because of its potentially slower onset of action, and monotherapy should always proceed in the WFSBP guidelines. Finally, concerning the treatment of acute depression, the concordance rate with the APA or WFSBP guidelines was much lower, that is, $5.6 \%$ with the APA guidelines and $11.9 \%$ with the WFSBP guidelines. This latter quantitative evidence is in line with Western reports, pointing out a major impact of polypharmacy in determining poor adherence toward standard prescription guidelines, especially in the case of antipsychotic polypharmacy in the inpatient and/or the inmate units. ${ }^{36}$

\section{Discussion \\ Study limitations and implications and premises}

Most of the limitations of the present systematic review are intrinsically related to the potential biases hampering the validity of the included studies and should be taken into account in the interpretations of the overall results presented herein. For example, given that medication decisions may be especially driven by mood episode polarity (eg, antidepressants prescribed for a depressive vs a manic episode), the fact that a number of included studies did not punctually stratify their own results using mood episode polarity as covariate in any multivariate analysis of significant univariate effect (if ever carried) should be considered. The inconsistency of the operative definitions of polypharmacy invariably affects the generalizability of the quantitative and qualitative results too, even if we strived to stratify our own results accordingly. Specifically, the ORs and risk ratios of the given studies included in the present review may differ across different studied samples according to the operative definitions of polypharmacy, sex, history of suicide attempt, associated medical and/or psychiatric clinical correlates, and Cohen's $d$ effect sizes could be documented or extracted whenever possible only. Publication and measurement (namely "diagnostic 
shift") biases should also be regarded. Indeed, most of the recently introduced SGA or novel antidepressant drugs could not be assessed by previous studies. In addition, little is known about specific regional or cultural settings despite the potential impact of either cultural or pharmacoeconomic issues on prescription trends across different high resource regions, ${ }^{80,81}$ although strikingly high prevalence rates of polypharmacy were documented even in nonhigh resource settings worldwide, especially when permissive operative criteria were adopted. ${ }^{28,31,82}$ With respect to low-income and/ or non-Western regions, even when such information was available, it often came from outdated or generic reports. For example, low rates of "affective psychosis" in contrast to "schizophrenia" cases were documented in Nigeria based on pharmacological treatment records dating back to the late $1970 \mathrm{~s} .{ }^{83}$ Yet, much higher prevalence rates of "affective disorders" was documented in the same region by a more recent multidiagnostic study focusing on polypharmacy. ${ }^{84}$ In this regard, we speculate that a diagnostic shift from schizophrenia to "affective disorders", in the broader sense, thus encompassing BD too, may reflect either differential settings (in- vs outpatient facilities) or the diagnostic revisions occurred within the past decades. ${ }^{81,85,86}$ These are additional crucial issues in the interpretation of cumulative evidence on polypharmacy "in BD" obtained from studies published within a large time frame beyond the sole "regional setting" variable. Finally, it is worth mentioning that while the stringent selection criteria adopted through this qualitative and quantitative review greatly reduced the number of contributes considered of adequate quality, this systematic selection ideally emphasized just the most rigorous and clinically relevant results on the topic, which is also a critical issue for the topic at issue considering the discrepancy exiting between real-world practice and the standard treatment guidelines on the matter.

\section{Final remarks and implications for the clinical practice}

[...] Doctors are men who prescribe medicines of which they know little, to cure diseases of which they know less, in human beings of whom they know nothing.

This much pessimistic quote was attributed to FrançoisMarie Arouet (1694-1778), best known by his nom de plume Voltaire. It was corroborated by the position of his countryman Philippe Pinel (1745-1826), who "was one of those physicians who reacted most strongly against the abuses of polypharmacy [multiple medications]" as René
Semelaigne wrote in 1888, a later-born psychiatrist whose family had memories of Pinel. ${ }^{87}$ This still reflects the attitude of many of modern prescribers toward BD polypharmacy.

Indeed, since 19th century, the practice of polypharmacy for what it is nowadays considered BD has spread consistently worldwide. It has been documented a tenfold increase in percentage of patients receiving three or more psychotropic medications at discharge between 1974 and $1995,{ }^{88}$ with much higher rates virtually occurring within the past 2 decades due to the increasing availability of novel pharmacological compounds, including antidepressant and SGA drugs, in the absence of any novel "silver bullet" drug for $\mathrm{BD}$ after the introduction of lithium. ${ }^{7,89,90}$

While a firm position either in support or against the practice of polypharmacy in BD is out of the scope (and the possibility) of the present evidence-based qualitative and quantitative synthesis, it is nonetheless worth noting that polypharmacy for BD is an extremely common scenario, often poorly, scientifically sound. Not all of the polypharmacy routine follow a pharmacological and/or diagnostic rationale or the standard guidelines, with the ultimate risk of further burden on the patents rather than additional benefit. Thus, it is mandatory that future replication studies will expand the current knowledge about the prevalence and the clinical features of polypharmacy testing the reliability and validity of different operative definitions, ideally focusing on selective clinically sound potential moderators currently precluding any reliable quantitative extraction on the matter beyond the qualitative synthesis provided by a systematic review, with a special emphasis toward affective temperaments, history of suicidal behavior, and/or rapid cycling and mixed features, especially considering that the ultimate goal in the management of BD should be paving the ground for long-term stability (thus regarding efficacy, tolerability, sustainability, and adherence issues) rather than merely focusing on the acute phase management.

\section{Author contributions}

MF conceived the study. BS and DV assisted in study procedures. DDB, ASK, GP, and AV contributed to manuscript drafting and interpretation of the results. All authors contributed toward data analysis, drafting and critically revising the paper and agree to be accountable for all aspects of the work.

\section{Disclosure}

The authors report no conflicts of interest in this work. 


\section{References}

1. Patten SB, Beck C. Major depression and mental health care utilization in Canada: 1994 to 2000. Can J Psychiatry. 2004;49(5): 303-309.

2. Kukreja S, Kalra G, Shah N, Shrivastava A. Polypharmacy in psychiatry: a review. Mens Sana Monogr. 2013;11(1):82-99.

3. Goldberg JF, Brooks JO 3rd, Kurita K, et al. Depressive illness burden associated with complex polypharmacy in patients with bipolar disorder: findings from the STEP-BD. J Clin Psychiatry. 2009;70(2): 155-162.

4. Zarate CA Jr, Quiroz JA. Combination treatment in bipolar disorder: a review of controlled trials. Bipolar Disord. 2003;5(3):217-225.

5. Preskorn SH, Lacey RL. Polypharmacy: when is it rational? J Psychiatr Pract. 2007;13(2):97-105.

6. McInerney SJ, Kennedy SH. Review of evidence for use of antidepressants in bipolar depression. Prim Care Companion CNS Disord. 2014; $16(5)$.

7. Fornaro M, Martino M, De Pasquale C, Moussaoui D. The argument of antidepressant drugs in the treatment of bipolar depression: mixed evidence or mixed states? Expert Opin Pharmacother. 2012;13(14): 2037-2051.

8. El-Mallakh RS, Gao Y, Jeannie Roberts R. Tardive dysphoria: the role of long term antidepressant use in-inducing chronic depression. Med Hypotheses. 2011;76(6):769-773.

9. Zigman D, Blier P. A framework to avoid irrational polypharmacy in psychiatry. J Psychopharmacol. 2012;26(12):1507-1511.

10. Sachs GS, Thase ME, Otto MW, et al. Rationale, design, and methods of the systematic treatment enhancement program for bipolar disorder (STEP-BD). Biol Psychiatry. 2003;53(11):1028-1042.

11. Perlis RH, Ostacher MJ, Patel JK, et al. Predictors of recurrence in bipolar disorder: primary outcomes from the systematic treatment enhancement program for bipolar disorder (STEP-BD). Am J Psychiatry. 2006;163(2):217-224.

12. Lin D, Mok H, Yatham LN. Polytherapy in bipolar disorder. CNS Drugs. 2006;20(1):29-42.

13. Perugi G, Fornaro M. Bipolar disorder treatment guidelines and their limits in every day clinical practice. Giorn Ital Psicopat. 2011;17(3): 261-264

14. Vieta E. Treatment guidelines for bipolar disorder: a bit unrealistic, but indispensable. Giorn Ital Psicopat. 2010;16:380-388.

15. Ghaemi SN. Polypharmacy in Psychiatry. Abingdon: Taylor \& Francis; 2002.

16. Niculescu AB 3rd. Polypharmacy in oligopopulations: what psychiatric genetics can teach biological psychiatry. Psychiatr Genet. 2006; 16(6):241-244.

17. Healy D, editor. Psychiatric Drugs Explained. 5th ed. London: Elsevier; 2009.

18. Paris J. The Use and Misuse of Psychiatric Drugs: An Evidence-Based Critique. Hoboken, NJ: John Wiley \& Sons; 2010.

19. Gallego JA, Bonetti J, Zhang J, Kane JM, Correll CU. Prevalence and correlates of antipsychotic polypharmacy: a systematic review and meta-regression of global and regional trends from the 1970s to 2009 . Schizophr Res. 2012;138(1):18-28.

20. Moher D, Liberati A, Tetzlaff J, Altman DG; PRISMA Group. Preferred reporting items for systematic reviews and meta-analyses: the PRISMA statement. PLoS Med. 2009;6(7):e1000097.

21. Qi X, Yang M, Ren W, et al. Find duplicates among the PubMed, EMBASE, and Cochrane Library Databases in systematic review. PLoS One. 2013;8(8):e71838.

22. McGauran N, Wieseler B, Kreis J, Schüler YB, Kölsch H, Kaiser T. Reporting bias in medical research - a narrative review. Trials. 2010; 11:37.

23. Sachs GS, Peters AT, Sylvia L, Grunze H. Polypharmacy and bipolar disorder: what's personality got to do with it? Int $J$ Neuropsychopharmacol. 2014;17(7):1053-1061.

24. Howland RH. Pharmacotherapy of inpatients with bipolar depression. Ann Clin Psychiatry. 1997;9(4):199-202.
25. Haeberle A, Greil W, Russmann S, Grohmann R. Mono- and combination drug therapies in hospitalized patients with bipolar depression. Data from the European drug surveillance program AMSP. BMC Psychiatry. 2012;12:153.

26. Kupfer DJ, Frank E, Grochocinski VJ, Cluss PA, Houck PR, Stapf DA. Demographic and clinical characteristics of individuals in a bipolar disorder case registry. J Clin Psychiatry. 2002;63(2):120-125.

27. Weinstock LM, Gaudiano BA, Epstein-Lubow G, Tezanos K, Celis-Dehoyos CE, Miller IW. Medication burden in bipolar disorder: a chart review of patients at psychiatric hospital admission. Psychiatry Res. 2014;216(1):24-30.

28. Hung GC, Yang SY, Chen Y, Lin SK. Psychotropic polypharmacy for the treatment of bipolar disorder in Taiwan. Psychiatr Serv. 2014; 65(1):125-128.

29. Baek JH, Ha K, Yatham LN, et al. Pattern of pharmacotherapy by episode types for patients with bipolar disorders and its concordance with treatment guidelines. J Clin Psychopharmacol. 2014;34(5): $577-587$.

30. Mauer S, Alahmari R, Vohringer PA, et al. International prescribing patterns for mood illness: the International Mood Network (IMN). J Affect Disord. 2014;167:136-139.

31. Okasha TA, Kucukalic A, Nasr AA, et al. Longer-term treatment of patients with bipolar disorder: a 9-month observational study in Central and Eastern Europe, the Middle East and Africa. Curr Med Res Opin. 2009;25(8):1889-1900.

32. Peindl KS, Masand P, Mannelli P, Narasimhan M, Patkar A. Polypharmacy in pregnant women with major psychiatric illness: a pilot study. $J$ Psychiatr Pract. 2007;13(6):385-392.

33. Greil W, Haberle A, Haueis P, Grohmann R, Russmann S. Pharmacotherapeutic trends in 2231 psychiatric inpatients with bipolar depression from the International AMSP Project between 1994 and 2009. J Affect Disord. 2012;136(3):534-542.

34. Bauer M, Glenn T, Alda M, et al. Drug treatment patterns in bipolar disorder: analysis of long-term self-reported data. Int J Bipolar Disord. 2013;1:5.

35. Bauer M, Glenn T, Grof P, et al. The association between concurrent psychotropic medications and self-reported adherence with taking a mood stabilizer in bipolar disorder. Hum Psychopharmacol. 2010;25(1): $47-54$.

36. Huffman JC, Chang TE, Durham LE, Weiss AP. Antipsychotic polytherapy on an inpatient psychiatric unit: how does clinical practice coincide with Joint Commission guidelines? Gen Hosp Psychiatry. 2011;33(5):501-508.

37. Gazalle FK, Hallal PC, Tramontina J, et al. Polypharmacy and suicide attempts in bipolar disorder. Rev Bras Psiquiatr. 2007;29(1):35-38.

38. Correll CU, Frederickson AM, Kane JM, Manu P. Does antipsychotic polypharmacy increase the risk for metabolic syndrome? Schizophr Res. 2007;89(1-3):91-100.

39. Baldessarini RJ, Perry R, Pike J. Factors associated with treatment nonadherence among US bipolar disorder patients. Hum Psychopharmacol. 2008;23(2):95-105.

40. Levine J, Chengappa KN, Brar JS, Gershon S, Kupfer DJ. Illness characteristics and their association with prescription patterns for bipolar I disorder. Bipolar Disord. 2001;3(1):41-49.

41. Levine J, Chengappa KN, Brar JS, et al. Psychotropic drug prescription patterns among patients with bipolar I disorder. Bipolar Disord. 2000; 2(2):120-130.

42. Adli M, Whybrow PC, Grof P, et al. Use of polypharmacy and selfreported mood in outpatients with bipolar disorder. Int $J$ Psychiatry Clin Pract. 2005;9(4):251-256.

43. Kamath J, Temporini H, Quarti S, et al. Best practices: disseminating best practices for bipolar disorder treatment in a correctional population. Psychiatr Serv. 2010;61(9):865-867.

44. Morrato EH, Dodd S, Oderda G, Haxby DG, Allen R, Valuck RJ. Prevalence, utilization patterns, and predictors of antipsychotic polypharmacy: experience in a multistate Medicaid population, 1998-2003. Clin Ther. 2007;29(1):183-195. 
45. Centorrino F, Cincotta SL, Talamo A, et al. Hospital use of antipsychotic drugs: polytherapy. Compr Psychiatry. 2008;49(1):65-69.

46. Centorrino F, Goren JL, Hennen J, Salvatore P, Kelleher JP, Baldessarini RJ. Multiple versus single antipsychotic agents for hospitalized psychiatric patients: case-control study of risks versus benefits. Am J Psychiatry. 2004;161(4):700-706.

47. Aparasu RR, Jano E, Bhatara V. Concomitant antipsychotic prescribing in US outpatient settings. Res Soc Adm Pharm. 2009;5(3):234-241.

48. Jordanova V, Maric NP, Alikaj V, et al. Prescribing practices in psychiatric hospitals in Eastern Europe. Eur Psychiatry. 2011;26(7):414-418.

49. Dols A, Rhebergen D, Beekman A, Kupka R, Sajatovic M, Stek ML. Psychiatric and medical comorbidities: results from a bipolar elderly cohort study. Am J Geriatr Psychiatry. 2014;22(11):1066-1074.

50. Hurley AD, Folstein M, Lam N. Patients with and without intellectual disability seeking outpatient psychiatric services: diagnoses and prescribing pattern. $J$ Intellect Disabil Res. 2003;47(pt 1):39-50.

51. Bauer R, Glenn T, Alda M, et al. Antidepressant dosage taken by patients with bipolar disorder: factors associated with irregularity. Int J Bipolar Disord. 2013;1:26.

52. Bushardt RL, Massey EB, Simpson TW, Ariail JC, Simpson KN. Polypharmacy: misleading, but manageable. Clin Interv Aging. 2008;3(2): 383-389.

53. Gillette C, Prunty L, Wolcott J, Broedel-Zaugg K. A new lexicon for polypharmacy: implications for research, practice, and education. Res Social Adm Pharm. 2015;11(3):468-471.

54. Jorgensen T, Johansson S, Kennerfalk A, Wallander MA, Svärdsudd K. Prescription drug use, diagnoses, and healthcare utilization among the elderly. Ann Pharmacother. 2001;35(9):1004-1009.

55. Linjakumpu T, Hartikainen S, Klaukka T, Veijola J, Kivelä SL, Isoaho R. Use of medications and polypharmacy are increasing among the elderly. J Clin Epidemiol. 2002;55(8):809-817.

56. Lopez-Torres Hidalgo J, Cerda Diaz R, Fernandez Olano C, Requena Gallego M, Fernández Casalderrey C, Otero Puime A. [Factors associated with chronic drug consumption in the elderly]. Med Clin. 1997;108(15):572-576.

57. Kingsbury SJ, Yi D, Simpson GM. Psychopharmacology: rational and irrational polypharmacy. Psychiatr Serv. 2001;52(8):1033-1036.

58. Krishnan KR. Psychiatric and medical comorbidities of bipolar disorder. Psychosom Med. 2005;67(1):1-8.

59. Kupfer DJ. The increasing medical burden in bipolar disorder. JAMA. 2005;293(20):2528-2530.

60. Engel RR, Grohmann R, Ruther E, Hippius H. Research methods in drug surveillance. Pharmacopsychiatry. 2004;37(suppl 1):S12-S15.

61. Grohmann R, Engel RR, Ruther E, Hippius H. The AMSP drug safety program: methods and global results. Pharmacopsychiatry. 2004;37(suppl 1):S4-S11.

62. Azorin JM, Aubrun E, Bertsch J, Reed C, Gerard S, Lukasiewicz M. Mixed states vs pure mania in the French sample of the EMBLEM study: results at baseline and 24 months - European mania in bipolar longitudinal evaluation of medication. BMC Psychiatry. 2009; 9:33.

63. Baldessarini R, Henk H, Sklar A, Chang J, Leahy L. Psychotropic medications for patients with bipolar disorder in the United States: polytherapy and adherence. Psychiatr Serv. 2008;59(10):1175-1183.

64. Hayes J, Prah P, Nazareth I, et al. Prescribing trends in bipolar disorder: cohort study in the United Kingdom THIN primary care database 1995-2009. PLoS One. 2011;6(12): 28725.

65. Quante A, Zeugmann S, Regen F, Engelhardt A, Anghelescu IG. Psychopharmacological treatment status in outpatients with bipolar disorder: a clinical survey in Germany. Psychiatry Investig. 2010;7(3): 155-162.

66. WHO. WHO Collaborating Centre for Drug Statistics Methodology. ATC/DDD Index 2011. Geneva: World Health Organization; 2013.

67. Barnett JH, Huang J, Perlis RH, et al. Personality and bipolar disorder: dissecting state and trait associations between mood and personality. Psychol Med. 2011;41(8):1593-1604.
68. Correll CU, Detraux J, De Lepeleire J, De Hert M. Effects of antipsychotics, antidepressants and mood stabilizers on risk for physical diseases in people with schizophrenia, depression and bipolar disorder. World Psychiatry. 2015;14(2):119-136.

69. Vincenti A, Ventriglio A, Baldessarini RJ, Talamo A, Fitzmaurice G, Centorrino F. Characteristics and clinical changes during hospitalization in bipolar and psychotic disorder patients with versus without substance-use disorders. Pharmacopsychiatry. 2010;43(6): 225-232.

70. Kamath J, Wakai S, Zhang W, Kesten K, Shelton D, Trestman R. Adaptation of the Texas implementation medication algorithm for bipolar disorder in adult female offenders. Int J Offender Ther Comp Criminol. Epub 2015 Mar 31.

71. Dautzenberg G, Lans L, Meesters PD, et al. The care needs of older patients with bipolar disorder. Aging Ment Health. Epub 2015 Jun 5: $1-9$.

72. Dias VV, Balanza-Martinez V, Soeiro-de-Souza MG, et al. Pharmacological approaches in bipolar disorders and the impact on cognition: a critical overview. Acta Psychiatr Scand. 2012;126(5):315-331.

73. Guillette LM, Hollis KL, Markarian A. Learning in a sedentary insect predator: antlions (Neuroptera: Myrmeleontidae) anticipate a long wait. Behav Processes. 2009;80(3):224-232.

74. Fornaro M, Ciampa G, Mosti N, Del Carlo A, Ceraudo G, Colicchio S. A case of treatment resistant depression and alcohol abuse in a person with mental retardation: response to aripiprazole and fluvoxamine therapy upon consideration of a bipolar diathesis after repetitive failure to respond to multiple antidepressant trials. Case Report Med. 2010; 2010:801514

75. Desai SD, Pandya RH. Study of psychiatric comorbidity in patients with headache using a short structured clinical interview in a rural neurology clinic in Western India. J Neurosci Rural Pract. 2014;5(suppl 1): S39-S42.

76. Pincus SM, Gladstone IM, Ehrenkranz RA. A regularity statistic for medical data analysis. J Clin Monit. 1991;7(4):335-345.

77. Yatham LN, Kennedy SH, Schaffer A, et al. Canadian Network for Mood and Anxiety Treatments (CANMAT) and International Society for Bipolar Disorders (ISBD) collaborative update of CANMAT guidelines for the management of patients with bipolar disorder: update 2009. Bipolar Disord. 2009;11(3):225-255.

78. APA. American Psychiatric Association Practice Guidelines for the Treatment of Psychiatric Disorders: Compendium 2006. Arlington, VA: APA; 2006.

79. Grunze H, Vieta E, Goodwin GM, et al. The World Federation of Societies of Biological Psychiatry (WFSBP) guidelines for the biological treatment of bipolar disorders: update 2009 on the treatment of acute mania. World J Biol Psychiatry. 2009;10(2):85-116.

80. Fornaro M, Clementi N, Fornaro P. Medicine and psychiatry in Western culture: Ancient Greek myths and modern prejudices. Ann Gen Psychiatry. 2009;8:21.

81. Bromet EJ, Kotov R, Fochtmann LJ, et al. Diagnostic shifts during the decade following first admission for psychosis. Am J Psychiatry. 2011; 168(11):1186-1194.

82. Deshmukh SA, Ismail TS. Evaluation of psychotropic drugs use pattern among out patients attending psychiatry department at Government Medical College and Hospital, Nagpur: a cross sectional study. Int J Pharm Bio Sci. 2012;3(3):428-436.

83. Odejide AO. A study of the inpatient service of a Nigerian Psychiatric Hospital. Compr Psychiatry. 1980;21(4):302-307.

84. Adeponle AB, Obembe AO, Adeyemi SO, Suleiman GT. Polypharmacy in psychiatric out-patient practice in northern Nigeria. Afr J Psychiatry. 2007;10(4):215-218.

85. Lake CR. Schizophrenia Is a Misdiagnosis: Implications for the DSM-5 and the ICD-11. Berlin: Springer Science \& Business Media; 2012.

86. Chen YR, Swann AC, Burt DB. Stability of diagnosis in schizophrenia. Am J Psychiatry. 1996;153(5):682-686. 
87. René S. Philippe Pinel et son Oeuvre Au Point de Vue de la Médecine Mentale. London: Forgotten Books; 2013:130-131. [Original work published 1890].

88. Frye MA, Ketter TA, Leverich GS, et al. The increasing use of polypharmacotherapy for refractory mood disorders: 22 years of study. J Clin Psychiatry. 2000;61(1):9-15.
89. Fornaro M, Aguglia E, Dell'Osso L, Perugi G. Could the underestimation of bipolarity obstruct the search for novel antidepressant drugs? Expert Opin Pharmacother. 2011;12(18):2817-2831.

90. Blier P. The well of novel antidepressants: running dry. J Psychiatry Neurosci. 2010;35(4):219-220.

\section{Publish your work in this journal}

Neuropsychiatric Disease and Treatment is an international, peerreviewed journal of clinical therapeutics and pharmacology focusing on concise rapid reporting of clinical or pre-clinical studies on a range of neuropsychiatric and neurological disorders. This journal is indexed on PubMed Central, the 'PsycINFO' database and CAS, and is the official journal of The International Neuropsychiatric Association (INA). The manuscript management system is completely online and includes a very quick and fair peer-review system, which is all easy to use. Visit http://www.dovepress.com/testimonials.php to read real quotes from published authors.

Submit your manuscript here: http://www.dovepress.com/neuropsychiatric-disease-and-treatment-journal 